\title{
CRANIAL ALLOMETRY, SEXUAL DIMORPHISM AND AGE STRUCTURE IN SAMPLE OF THE EGYPTIAN WOLF CANISANTHUSLUPASTER MAHMOUD I. YOUNES AND FOUAD F. FOUAD
}

\author{
DEPARTMENT OF ZOOLOGY, FACULTY OF SCIENCE, AL AZHAR UNIVERSITY, NASR CITY, CAIRO, EGYPT
}

\section{ABSTRACT}

The study investigates the occurrence of age-related allometric changes in a number of cranial and dental measurements of the Egyptian wolf Canis anthus lupaster from different areas of Egypt.The age structure of a sample of 55 specimens of both sexes of C.a. lupaster was investigated using counting dentine layers on longitudinally sanded canine roots. The results showed that most of the wolves were between one and three years of age. The oldest individual was 11 years old. A set of isometric cranial and dental characters that qualify as diagnostic characters for analyzing interaspecific, morphological differentiation among populations of this and other closely related canids are identified.

Key words: Egyptian wolf; Canis; Allometry; Age structure; Sexual dimorphism; Increment layers

\section{INTRODUCTION}

The Egyptian wolf $C$. a.lupaster is a common wild canid throughout Egypt. Its taxonomic status, particularly its relationship with the gray wolf C. lupusand the golden jackal C.aureus has been a matter of debate during the past few years (Ruenesset al., 2011\&2015; Gaubertet al., 2012; Koepfliet al., 2015). Recently, however, detailed morphological (Saleh and Basuony, 2014) and molecular phylogenetic studies (Koepfliet al., 2015; Ruenesset al., 2015; Urios et al., 2015) have confirmed the distinct specific status in North African and the names $C$. lupaster and $C$. anthushave been used for its Nile Valley and northwestern African populations respectively (Saleh and Basuony, 2014; Koepfli et al., 2015; Ruenesset al., 2015; Urios et al., 2015). The phylogeography and taxonomic relationship between these two populations has been investigated by Fouad (2016).

As a species, distinct from its co-generic relative'sC. lupus and C. aureus, morphological and genetic differentiation among its populations throughout its vast range across North Africa becomes particularly important. Morphological comparison, however, requires that diagnostic morphological characters selected for that comparison are not affected by physiological condition of the individual, particularly its age. As such, identification of isometric characters that are not age related is particularly important.

Several methods, based on morphological indicators have been used for age determination in carnivores. These indicators include body weight, body length, cranial dimensions, dry weight of eye lens, extent of fusion of cranial sutures or devel- opment of the sagittal crest, tooth wear, occlusion of the dental pulp, or increments in dentine layers (Nelson and Chapman, 1982;Wandeler and Lups, 1993; Ansorge, 1994; Cavallini and Santini, 1995; Zapata et al., 1995). Among many methods based on analysis of changes in morphological characters, the dental cementum analysis method is a widely accepted method for age determination of many mammals (Adams and Watkins, 1967; Thomas and Bandy, 1973; Fancy, 1980) and is often considered the most exact age determination method (Nelson and Chapman, 1982;Cavallini and Santini, 1995; Zapata et al., 1995; Roulichova and Andera, 2007). Roulichova and Andera (2007) described a simplified method based on counting dentine layers in unstained sanded canine roots. The method allows the simple, yet reliable, age estimation from one year onwards.

A large geographically comprehensive collection of the Egyptian wolf \&DOSSDMHis available at the Al-Azhar University Zoological Collection (AUZC) in Cairo. In this study we use the dentine layer counting method as described by Roulichova and Andera(2007) to investigate the age structure of this large museum sample. We also assess the relationship between commonly used cranial and dental morphometric characters and both sex and age in order to provide basis for the sorting of isometric and allometric characters available for use of these as diagnostic characters in the taxonomy of this canid. Potential sexual dimorphism in the selected diagnostic characters is also examined.

\section{MARTIAL AND METHODS}

55 Egyptian wolf \&DD OSDMUU specimens of both sexes, deposited at the Al-Azhar Uni- 
versity Zoological Collection (AUZC), Department of Zoology, Faculty of Science, Al-Azhar University, Cairo were used. Age determination was carried out using the counting of the increment layers of secondary dental cement method as described by Roulichova and Andera (2007). The sample consists of specimens collected from areas throughout the country (Table 1) including Nile Valley, the Nile Delta, ElFaiyum Depression, Lake Nasser (west and east), the Western Mediterranean Coastal Desert and the inland Western Desert (Qattara Depression and Siwa Oasis).

In that method, one or both upper canine teeth are carefully extracted from the jaw (by hand or with dental forceps). The canine root is then sanded by hand, down to roughly half its thickness using sandpaper coarseness ca 80 then smoothed using coarseness ca 400 and finally polished at the very fine coarseness of ca 1200 . The preparation is then examined under a stereoscopic microscope at $25 \mathrm{x}$ magnification, without any staining. The age of the specimens that are more thana year old is estimated by simply counting the dark lines. The darkl ines are most satisfactorily discernible at the sides of the root close to its apex. The sample was divided into age groups of one year, $2-3$ and more than 3 years.

Table (2) showeda definition of standard cranial and dental characters investigated for potential allometric and isometric changes.Cranial and dental measurements were taken using a sliding caliper of the $0.1 \mathrm{~mm}$ accuracy.

Table 1: Localities and numbers of the Egyptian wolf specimens examined during this study

\begin{tabular}{|l|c|}
\hline Locality & Number ofspecimens \\
\hline Nile Valley and Delta & 49 \\
\hline Western Mediterranean Coastal Desert, Qattara Depression andSiwa Oasis & 6 \\
\hline Total Specimens & 55 \\
\hline
\end{tabular}

Table 2: Definition of cranial and dental characters used in the study

\begin{tabular}{|c|c|}
\hline Character & Definition \\
\hline GTL & $\begin{array}{l}\text { Greatest length of the skull: the greatest antero-posterior diameter of the skull, taken } \\
\text { dorsally from the most projecting point at each extremity, regardless of what structure } \\
\text { forms these points. }\end{array}$ \\
\hline CBL & $\begin{array}{l}\text { Condylobasal length: taken ventrally from an occipital condyle to the anterior extremity of } \\
\text { a premaxilla. }\end{array}$ \\
\hline BL & $\begin{array}{l}\text { Basal length: taken ventrally from the point between the two occipital condyles to the } \\
\text { anterior extremity of the skull. }\end{array}$ \\
\hline BCL & $\begin{array}{l}\text { Basicranial length:taken ventrally from the point between the two occipital condyles to the } \\
\text { base of the presphenoid. }\end{array}$ \\
\hline BFL & $\begin{array}{l}\text { Basifacial length:taken ventrally from the base of the presphenoid to the anterior } \\
\text { extremity of the skull. }\end{array}$ \\
\hline VCL & $\begin{array}{l}\text { Viscerocranial length: taken dorsally from the midpoint between the two nasals to the } \\
\text { anterior extremity of the skull. }\end{array}$ \\
\hline $\mathbf{F L}$ & $\begin{array}{l}\text { Facial length: Taken dorsally from the postorbital process to the anterior extremity of the } \\
\text { skull. }\end{array}$ \\
\hline $\mathbf{N L}$ & $\begin{array}{l}\text { Greatest length of nasals: taken dorsally from the midpoint between the two nasals to the } \\
\text { tip end of a nasal. }\end{array}$ \\
\hline SL & $\begin{array}{l}\text { Snout length: taken dorsally from anterior of the lacrimal bone to the anterior extremity of } \\
\text { the skull. }\end{array}$ \\
\hline $\mathbf{P L}$ & $\begin{array}{l}\text { Palatal length:taken ventrally from the tip of a palatine to the anterior extremity of the } \\
\text { skull. }\end{array}$ \\
\hline ABL & Greatest length of the auditory bulla: the maximum length of a bulla taken ventrally. \\
\hline GBM & $\begin{array}{l}\text { Greatest breadth across the mastoid processes: the maximum width from a mastoid } \\
\text { process to the other one taken ventrally or dorsally. }\end{array}$ \\
\hline ZB & $\begin{array}{l}\text { Zygomaticbreadth: the greatest width of the skull across the zygomatic arches, regardless } \\
\text { of where this point is situated along the length of the arches taken ventrally or dorsally. }\end{array}$ \\
\hline PC & $\begin{array}{l}\text { Least width of skull at the postorbital constrictions: the minimum distance behind the two } \\
\text { postorbital processes taken dorsally. }\end{array}$ \\
\hline FPW & $\begin{array}{l}\text { Frontal width across the postorbital processes: the maximum distance between the two } \\
\text { postorbital processes taken dorsally. }\end{array}$ \\
\hline IC & Inter-orbital constriction: the narrowest width across the interorbital region. \\
\hline MxPW & Maximum palatal width:taken ventrally from the end of the upper jaws internally. \\
\hline MnPW & Minimum palatal width: the least width of the snout taken ventrally or dorsally. \\
\hline CAW & $\begin{array}{l}\text { Width at canine alveoli: the maximum width of the alveoli of the two canines regardless } \\
\text { they are found or not taken ventrally or dorsally. }\end{array}$ \\
\hline
\end{tabular}


Cranial Allometry,Sexual Dimorphism and Age StructureinSample

\begin{tabular}{|c|c|}
\hline Character & Definition \\
\hline DBC & $\begin{array}{l}\text { Depth of braincase:taken laterally from the deepest point of the skull ventrally to the } \\
\text { highest point of it dorsally. }\end{array}$ \\
\hline IF & $\begin{array}{l}\text { Prosthion: taken dorsally from the infraorbital foramen to the anterior extremity of the } \\
\text { skull. }\end{array}$ \\
\hline FM & Taken laterally from the foramen magnum to the middle point of frontal. \\
\hline PDT & $\begin{array}{l}\text { Palatal depth behind tooth row: taken laterally from the end of an upper jaw to the } \\
\text { equivalent point at the roof of the skull. }\end{array}$ \\
\hline DIF & $\begin{array}{l}\text { Depth at infraorbital foramen: taken laterally from the infraorbital foramen to the above } \\
\text { point at the roof of the skull. }\end{array}$ \\
\hline BB & $\begin{array}{l}\text { Brain case breadth: the width of the braincase at the posterior roots of the zygomatic } \\
\text { arches. }\end{array}$ \\
\hline WAM & $\begin{array}{l}\text { Width across auditory meatus: the distance between the two external auditory meati } \\
\text { taken dorsally. }\end{array}$ \\
\hline BW & Bullar width: the greatest width of the tympanic bulla. \\
\hline WS & $\begin{array}{l}\text { The maximum width of the sagittal crest: at the posterior edge of the parietal bones taken } \\
\text { dorsally. }\end{array}$ \\
\hline MT & $\begin{array}{l}\text { Mandibular toothrow: from the tip point of a lower jaw to the last molar there even that } \\
\text { teeth are found or lost. }\end{array}$ \\
\hline M & Mandible length: from the tip point of a lower jaw to the angular process. \\
\hline GBO & Greatest breadth across the occipital condyles. \\
\hline MPU & $\begin{array}{l}\text { Molar premolar length: from beginning of the first premolar } \mathrm{PM}^{1} \text { to end of the last molar } \\
\mathrm{M}^{2} \text { in the upper jaw. }\end{array}$ \\
\hline IM & Incisor molar length: from the base of incisors to end of the last molar in the upper jaw. \\
\hline $\mathrm{PM}^{4}$ & Premolar ${ }^{4}$ Length:Length of fourth upper premolar. \\
\hline$M^{1}-M^{2}$ & Combined length of upper molars from anterior edge of $\mathrm{M}^{1}$ to posterior edge of $\mathrm{M}^{2}$. \\
\hline MDTR & $\begin{array}{l}\text { Mandibular tooth row: length of mandibular tooth row from the front of the lower canine } \\
\text { to the back of the crown of the last lower molar. }\end{array}$ \\
\hline
\end{tabular}

Table 3. Age classes in Egyptian wolf samples from three geographical regions in Egypt

\begin{tabular}{|l|c|c|c|}
\hline \multirow{2}{*}{ Geographical region } & \multicolumn{3}{|c|}{ Percentage of age class in the sample } \\
\cline { 2 - 4 } & $\begin{array}{c}\text { Age class } \mathbf{1} \\
\mathbf{( 1 - < 2} \text { years })\end{array}$ & $\begin{array}{c}\text { Age class } \mathbf{2} \\
\mathbf{( 2 - 3} \text { years })\end{array}$ & $\begin{array}{c}\text { Age class } \mathbf{3} \\
\text { ( } \mathbf{3} \text { year) }\end{array}$ \\
\hline Nile Valley and Delta & $39 \%$ & $35 \%$ & $26 \%$ \\
\hline Qattara Depression and Siwa Oasis & $67 \%$ & $0.0 \%$ & $33 \%$ \\
\hline TOTAL & $\mathbf{4 2 \%}$ & $\mathbf{3 1 \%}$ & $\mathbf{2 7 \%}$ \\
\hline
\end{tabular}

Table 4. Mean, standard deviation, range and sample size of isometric cranial ratios of the Egyptian wolf from Nile Valley and Delta

\begin{tabular}{|l|c|c|c|}
\hline Character & Age class 1 (one year) & Age class 2 (2-3 years) & Age class 3 (> 3 years) \\
\hline BL/CBL & $0.94 \pm 0.01(0.93-0.96) 22$ & $0.94 \pm 0.01(0.92-0.96) 16$ & $0.94 \pm 0.01(0.93-0.95) 15$ \\
\hline NL/VCL & $0.76 \pm 0.02(0.73-0.79) 25$ & $0.76 \pm 0.02(0.72-0.80) 18$ & $0.76 \pm 0.02(0.71-0.78) 14$ \\
\hline IC/ZB & $0.34 \pm 0.02(0.30-0.39) 23$ & $0.34 \pm 0.02(0.31-0.36) 16$ & $0.34 \pm 0.02(0.31-0.38) 15$ \\
\hline MnPW/ZB & $0.31 \pm 0.02(0.27-0.35) 23$ & $0.31 \pm 0.01(0.29-0.33) 16$ & $0.31 \pm 0.02(0.27-0.34) 15$ \\
\hline IF/CBL & $0.33 \pm 0.01(0.31-0.35) 22$ & $0.33 \pm 0.01(0.31-0.34) 16$ & $0.33 \pm 0.01(0.32-0.35) 15$ \\
\hline PDT/CBL & $0.27 \pm 0.01(0.24-0.29) 22$ & $0.27 \pm 0.01(0.26-0.28) 16$ & $0.27 \pm 0.01(0.24-0.29) 15$ \\
\hline WAM/ZB & $0.58 \pm 0.02(0.55-0.61) 22$ & $0.58 \pm 0.02(0.55-0.63) 14$ & $0.58 \pm 0.02(0.55-0.62) 15$ \\
\hline BW/ZB & $0.19 \pm 0.01(0.17-0.21) 22$ & $0.19 \pm 0.01(0.17-0.21) 16$ & $0.19 \pm 0.02(0.17-0.22) 15$ \\
\hline BW/WAM & $0.33 \pm 0.02(0.30-0.36) 22$ & $0.33 \pm 0.02(0.30-0.36) 16$ & $0.33 \pm 0.02(0.30-0.38) 15$ \\
\hline WS/CBL & $0.02 \pm 0.01(0.01-0.04) 22$ & $0.02 \pm 0.01(0.01-0.03) 16$ & $0.02 \pm 0.01(0.01-0.04) 15$ \\
\hline GBO/ZB & $0.35 \pm 0.02(0.32-0.39) 22$ & $0.35 \pm 0.02(0.32-0.38) 15$ & $0.35 \pm 0.02(0.32-0.37) 15$ \\
\hline WS/ZB & $0.04 \pm 0.01(0.02-0.07) 23$ & $0.04 \pm 0.01(0.02-0.06) 16$ & $0.04 \pm 0.01(0.02-0.07) 15$ \\
\hline WS/FPW & $0.08 \pm 0.03(0.04-0.14) 23$ & $0.08 \pm 0.02(0.04-0.12) 15$ & $0.08 \pm 0.03(0.05-0.16) 15$ \\
\hline
\end{tabular}


Table 5. External and cranial morphometric characters showing significant sexual dimorphism in C. a. lupaster

\begin{tabular}{|c|c|c|c|c|c|c|c|}
\hline SEX & BM & BM/HBL & TL/HBL & ZB/GTL & ZB/CBL & PL/GTL & ABL/ZB \\
\hline Male & 16.00 & 17.92 & 0.42 & 0.54 & 0.57 & 0.49 & 0.23 \\
\hline Female & 13.50 & 14.93 & 0.35 & 0.52 & 0.55 & 0.50 & 0.25 \\
\hline SEX & IC/GTL & MxPW/GTL & MxPW/CBL & MxPW/BB & MnPW/GTL & MnPW/CBL & MnPW/BB \\
\hline Male & 0.19 & 0.32 & 0.34 & 1.09 & 0.17 & 0.18 & 0.58 \\
\hline Female & 0.18 & 0.31 & 0.33 & 1.05 & 0.16 & 0.17 & 0.55 \\
\hline SEX & FM/ZB & GBO/BB & & & & & \\
\hline Male & 0.85 & 0.64 & & & & & \\
\hline Female & 0.90 & 0.62 & & & & & \\
\hline
\end{tabular}
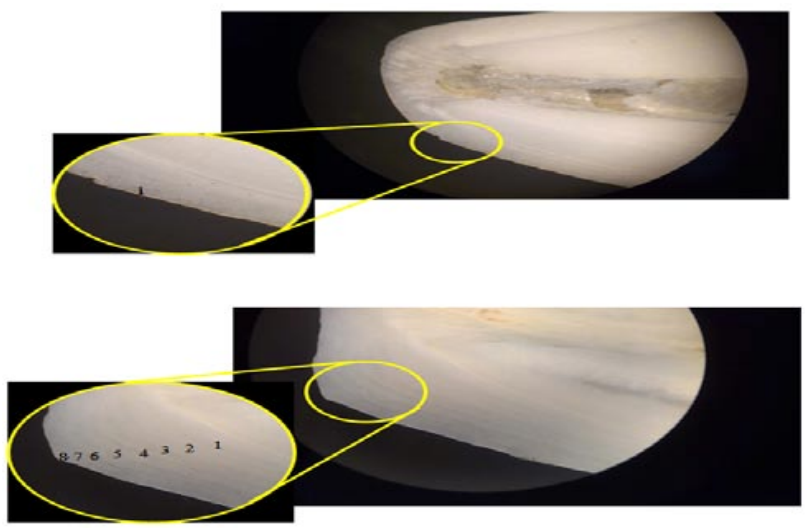

Figure 1.Annual layers of secondary dental cement in a canine tooth of a one year (top) and 8 years (bottom) old Egyptian wolves $\llbracket$. a.lupaster
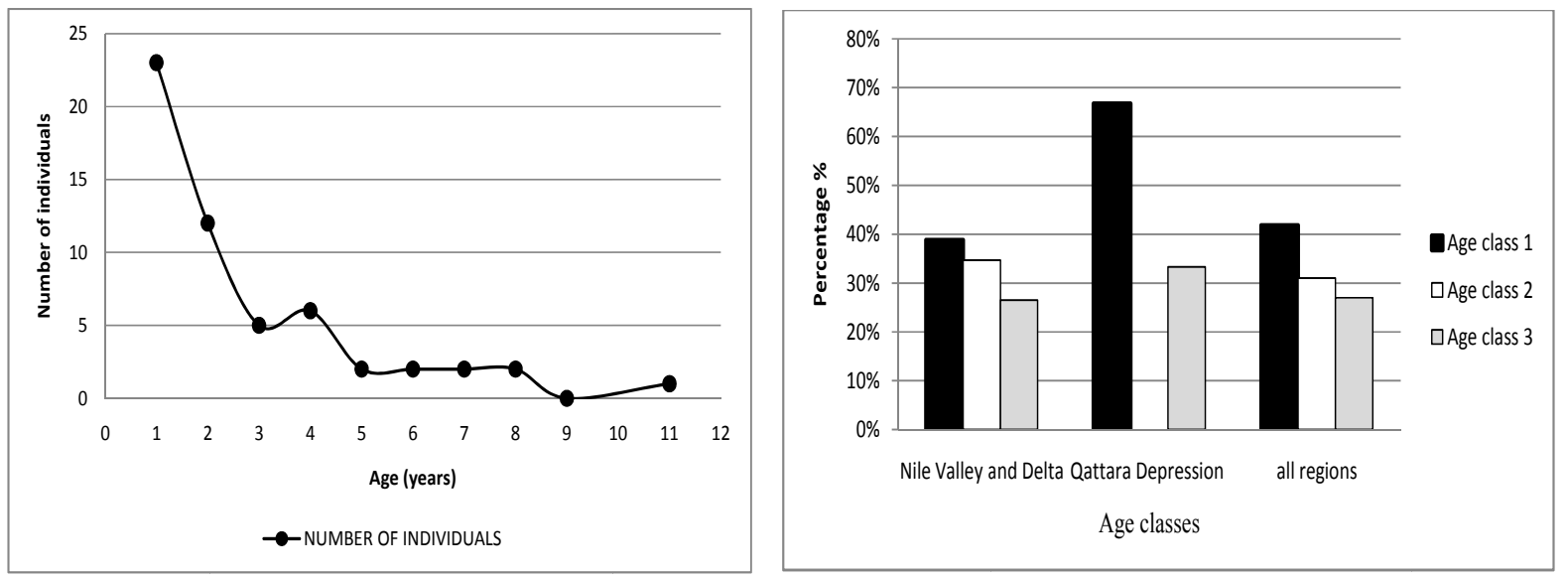

Figure 2. Age structure in a sample of 55 individuals Figure 3.The Egyptian wolf C.a. lupaster age classes of the Egyptian wolf C.a. lupaster

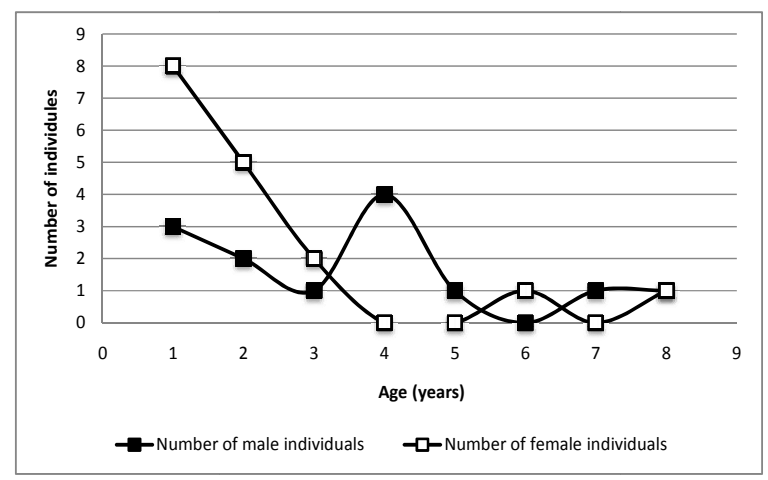
in different geographical regions in Egypt

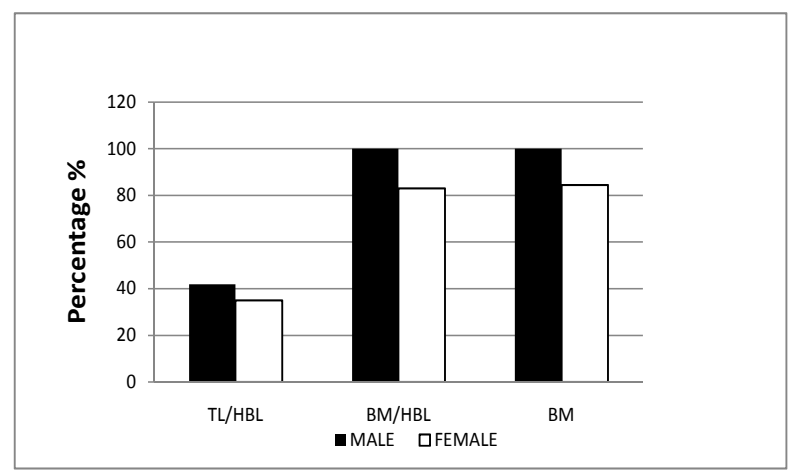

Figure 4. Age structure in a sample of 31 (14 males, Figure 5. External morphometric characters showing 17females) of the Egyptian wolf 


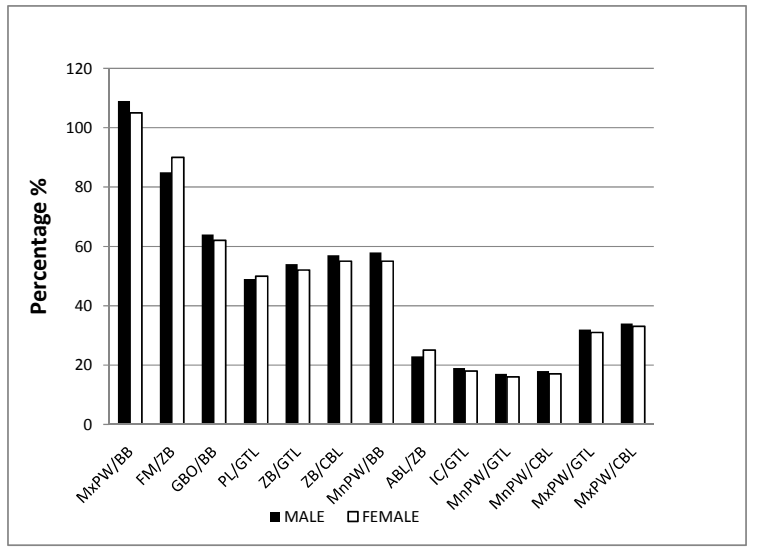

Figure 6. Cranial morphometric characters showing significant sexual dimorphism in C. a. lupaster
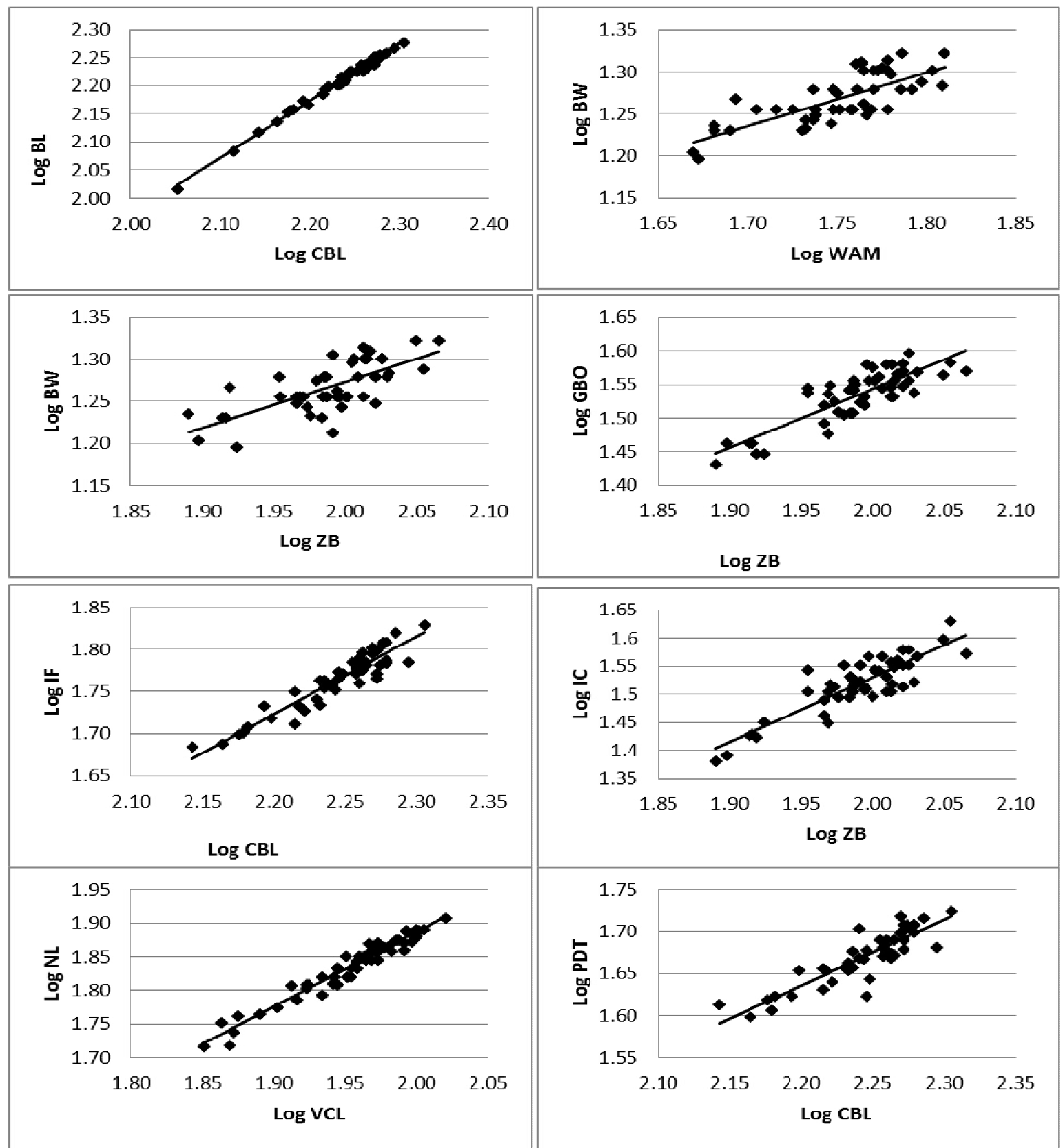

Figure 7. Isometric morphologic characters in C.a. lupaster populations of different age groups 


\section{RESULTS AND DISCUSSION}

Figure (1) showed examples of the dentine layers in animals of different ages in the sample. The method appeared reliable and was easily applicable to a wide spectrum of age classes covering the entire study of 55 adult Egyptian wolves. The method depends on counting the annual dentine rings, the resolution of the methods is one year. Fractions of a year or ages of animals of less than one year could not be detected using this method. It should be noted, however, that most of the specimens in the study collection were collected in the winter, which make them at least one year old (born the previous winter) as the Wolves are born during the winter.

The results showed that age in a sample of 55 adult skulls ranges between one year and 11 years with the mean age of a sample being 2.69 years $(\mathrm{SD} \pm 2.25)$. Figure (2) showedthe age structure in the sample. It is clear from the figure that the great majority of the wolves are in the one year age class (showing one canine dentine ring).

Mortality seems to be moderate, resulting in a life span that seems to be somewhat shorter than the natural life expectancy with the $42 \%$ of animals in the sample being adults of less than two years of age (Fig.3). The reason for this relative dominance of the youngest age group among adults is not clear. Assuming that the sample actually represents the age structure of the population, the data shows that half of the adult wolves lose their life before reaching their second year of age. By the third year, $73 \%$ of the wolves would have lost their lives(Fig. 3). Older wolves of more than three years of age seem to represent a good stable percentage of the population until the eight years of age when the percentage of wolves of more than eight years of age declines indicating approaching the maximum life expectancy.

It should be noted, however, that most of the animals in the samples are collected using leg-hold traps. It may be assumed that the age structure of the sample reflects or is at least significantly affected by the trapability of the different age classes. It may be assumed that the young, un-experienced animals are easier to fall in the trap. As animals become older, they become more experienced and are more difficult to trap. The figure also showed a relatively stable percentage of older animals in the sample, which may suggest that older, more experienced animals are more capable avoiding life-threatening dangers and unfavorable condition.

Animals in the sample may be grouped into three age classes as follows:

- Age class 1 . These are animals with one canine dentine ring and range in age from one year to just under two years of age.

- Age class 2. Animals with two to three canine dentine rings representing an age range between two to four years of age.

- Age class 3. This class includes all animals showing four or more canine dentine rings representing four or more years of age.

Age structure in wolf samples based on these age classes from different regions are shown in Table 3. Three wolf populations corresponding to two geographical regions in Egypt are considered for this analysis. Age class 1 is represented by the largest percentage in the sample. The dominance of the age class 1 , and by inference, the life expectancy beyond two years of age varies in different sampling regions (Table 3 and Fig. 3). In the Nile Valley, the Nile Delta and El Faiyumsignificant percentages of animals in the three age classes, including the older age class 3 were present. In comparison, the percentage of older animals in the samples from the Qattara Depression and Siwa Oasis was much lower with $67 \%$ in age class 1 and $33 \%$ in age class 3 . This may suggest that the wolves living in the mesic, high productivity Nile Valley and Delta habitats with abundance of resources survive longer than their desert counterpart where food resources are limited and environmental conditions are much harsher.

In our sample of sexed skulls, the average age of the females ( 2.24 years) is lower than that of the males (3.54 years) (Fig. 4). If the sample adequately represents the natural population, the lower average age of females may either indicate one feature of sexual dimorphism of this species. 
It may equally indicate that young female wolves are more easily trapped than older ones and are therefore over-represented in the sample.

The majority of the Egyptian wolf \& $D \amalg O S D M U U$ trapping in Egypt takes place in the Nile Valley, Nile Delta and El Faiyum. Although no commercial trapping takes place in the Western Desert Oases and the Western Mediterranean Coastal Desert regions, poisoning of carnivores (foxes and jackals) is often practiced in the inhabited and cultivated areas of these regions. The extent of the poisoning campaigns and their impact on the wild carnivore populations in this area is often mentioned in the literature (Osborn and Helmy, 1980; Saleh and Basuony, 2014), but their magnitude and frequency are not known. It seems, however, that the impact of trapping activities in the Nile Valley and Delta region is tolerated as a result of the abundance of food and habitat resources in that region in comparison with the meager resources in available to the desert-dwelling wolves. The Egyptian wolf populations in the Nile valley and Delta seem to remain viable with a large percentage of young wolves in the population. The high reproductive rate of this wolf seems to allow the species to tolerate this intensive harvesting of this wolf.

\section{Sexual Dimorphism}

Our results confirm the frequently reported size sexual dimorphism in this species and other members of the genus Canis with the males averaging significantly larger than females (Osborn and Helmy, 1980; Hillis and Mallory, 1996). Figure (5)showed that males average $15.6 \%$ heavier than females. The ratio of BM/HBL in the female averages lower than that in males making the female appearing more lightly built than the male. The males' relatively heavy built seems to be caused by their larger muscle masssuitable for defending territory and possibly for capturing and killing larger prey.The TL/HBL ratio in fem that of males, which

may indicate that the females have relatively shorter tails than males (Fig. 5).

Sexual dimorphism is also apparent in body proportions, particularly cranial ratios. The 36 cranial characters examined in our sample adult animals of both sexes and 17 ratios showed significant sexual dimorphism (Table 5 \& Fig.6). Based on comparing these ratios, the skull of the male is relatively wider than that of female and the female appears to have a more pointed snout. Within this general difference, sexual dimorphism in the shape of the head is manifested in the ratios (Table 5 \& Fig.6).

\section{, VRP HMF DQG \$ CAP HMFO RLSKRORIFDO \&KDUDWU}

The examined 36 cranial characters and their ratiosin the adult animals of different age groups to identify potential diagnostic characters do not show significant allometric changes with age (Fig. 7). Ratios of these characters, which are often used as diagnostic taxonomic characters are tested for significant allometricgrowth tendencies with age. Identified isometric (non-allometric) characters and ratios will constitute the basic tool kit for identification and segregation of intraspecific morphological differences in this species. Allometric characters will not be used in the analysis of morphological structuring and differentiation of different Canis taxa. Table (4) and Figure (7) showedthe selected 13 non-allometric (isometric) cranial and dental character that are suitable for morphological comparison of different populations irrespective of the age of the specimen. These characters showed very little change with age once the animal reaches adulthood.

The above result clearly identifies a number of key morphological characters that can be safely used to detect and compare morphological differences among populations of the Egyptian wolf populations and closely related taxa. The accurate identification of such characters is crucial to any future analysis of this enigmatic species with its seemingly disjunct distribution across a vast area of extremely arid desert.

\section{REFERENCES}

1. Adams, L. and Watkins, S.G. (1967): Annuli in tooth cementum indicate age in California ground squirrels. The Journal of Wildlife Management, 30(4): 836-839.

2. Ansorge, H. (1994): Intrapopular skull variability in the red fox, Vulpesvulpes (Mammalia: Carnivora: Canidae). ZoologischeAbhandlungenausdemstaatlichen Museum fürTierkunde in Dresden, 48: 103-123. 
3. Cavallini, P. and Santini, S. (1995): Age determination in the Red fox in a Mediterranean habitat. ZeitschriftfürSäugetierkunde, 60: 136-142.

4. Fancy, S.G. (1980): Preparation of animal teeth for age determination by cementum layers: a review. Wildlife. Society. Bulletin, 8: 242-248.

5. Fouad, F.F. (2016):Molecular zoogeography of mammals of the genus Canis in Egypt. M.Sc. Thesis, Al Azhar University, Nasr City, Cairo, Egypt.

6. Gaubert, P.; Bloch, C.; Benyacoub, S.; AbdElhamid, A.; Pagani, P.; Adeyemi, C. and Dufour, S. (2012): Reviving the African wolf Canis lupus lupaster in North and West Africa: a mitochondrial lineage ranging more than 6,000 km wide. PloS one, 7(8): e42740.

7. Hillis, T.L. and Mallory, F.F. (1996): Sexual dimorphism in wolves Canis lupus of the Keewatin District, Northwest Territories, Canada. Canadian Journal of Zoology, 74: 721-725.

8. Koepfli, K.P.; Pollinger, J.; Godinho, R.; Robinson, J.; Lea, A.; Hendricks, S. and Yurchenko, A.A. (2015): Genome-wide evidence reveals that African and Eurasian golden jackals are distinct species. Current Biology, 25(16): 2158-2165.

9. Nelson, B.B. and Chapman, J.A. (1982): Age determination and population characteristics of red foxes from Maryland. Zeitschrift fur Saugetierkunde, 47: 296311.

10. Osborn, D. and Helmy, I. (1980): The Contemporary Land Mammals of Egypt (Including Sinai). Fieldiana Zool. New Series, No. 5, pp.579.

11. Roulichova, J. and Andera, M. (2007): Simple method of age determination in red fox, Vulpesvulpes. Folia Zoologica, 56(4): 440-444.
12. Rueness, E.K.; Asmyhr, M.G.; Sillero-Zubiri, C.; Macdonald, D.W., Bekele, A.; Atickem, A. and Stenseth, N.C. (2011):The cryptic African wolf:Canisaureuslupaster is not a golden jackal and is not endemic to Egypt. PLoS One, 6(1): e16385.

13. Rueness, E.K.; Trosvik, P.; Atickem, A.; Sillero-Zubiri, C. and Trucchi, E. (2015): The African wolf is a missing link in the wolf-like canid phylogeny. bioRxiv, http://dx.doi.org/10.1101/017996.

14. Saleh, M.A. andBasuony, M.I. (2014): Mammals of the genus Canis Linnaeus, 1758 (Canidae; Carnivore) in Egypt. Egypt JZool, 62: 49-92.

15. Thomas, D.C. and Bandy, P.J. (1973): Age determination of wild black-tailed deer from dental annulations. The Journal of Wildlife Management, 37(2): 232-235.

16. Urios, V.; Donat-Torres, M.P.; Ramirez, C.; MonroyVilchis, O. and Rgribi-Idrissi, H. (2015): The analysis of the canid mitochondrial genome studied in Morocco shows that it is neither wolf (Canis lupus) nor Eurasian jackal (Canisaureus). Altotero. Vida salvaje / rewilding Spain, 3: 1-24.

17. Wandeler, A.I. and Lups, P. (1993): Vulpesvulpes (Linnaeus, 1758) - Rotfuchs. In: Niethammer, J. and Krapp F. (eds), Handbuch der SäugetiereEuropas, Band 5/1, Raubsäuger - Carnivora (Fissipedia), Teil I: Canidae, Ursidae, Procyonidae, Mustelidae 1. AULA - Verlag Wiesbaden, 138-185.

18. Zapata, S.C.; Travaini, A. and Delibes, M. (1995): Comparación entre variastécnicas de estimación de la edad en zorros, Vulpesvulpes, de Doñana (sur de la PenínsulaIbérica). DoñanaActa Vertebrata, 22(1-2): 29-50.

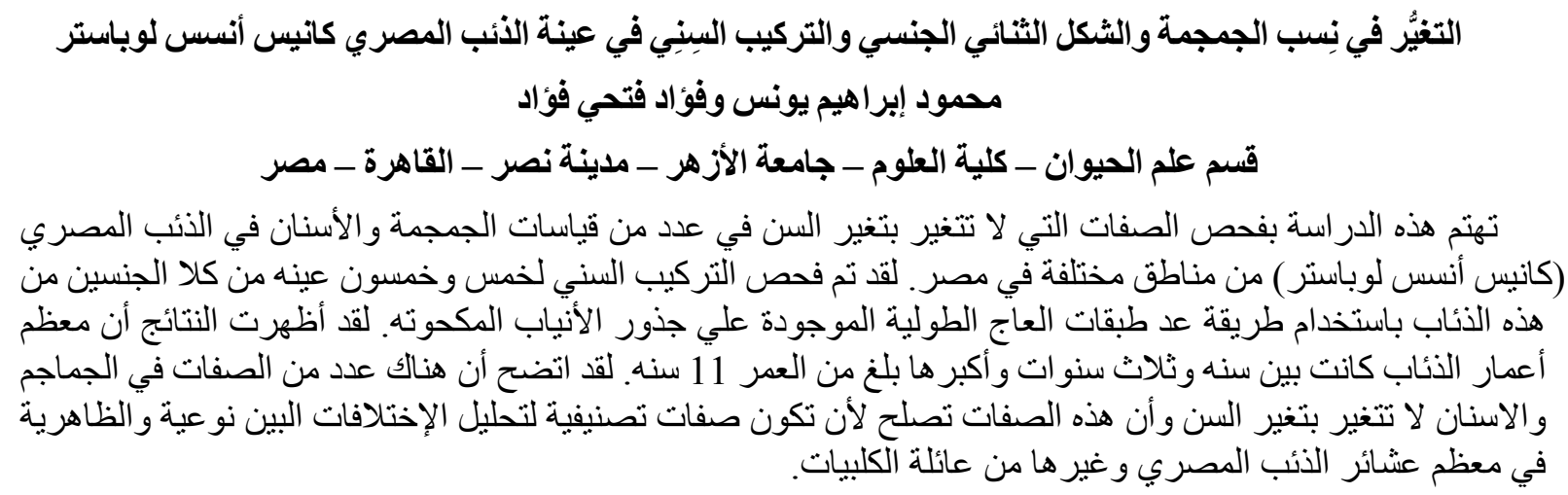

